\title{
ANÁLISIS DE UNA EXPRESIÓN GRÁFICA INÉDITA EN LA REGIÓN DE MURCIA: LOS GRAFITOS HISTÓRICOS DEL CAÑO DEL BARRACóN y de La TorRe de Inchola (Alhama de Murcia)
}

\author{
ANALYSIS OF AN UNPRECEDENTED GRAPHIC EXPRESSION IN THE REGION \\ of Murcia: The engravings of the Caño del Barracón \\ aNd THE TOWER OF Inchola (Alhama De Murcia)
}

\author{
Gregorio Rabal Saura * \\ Gregorio Castejón Porcel **
}

Recibido: 22/02/2020 • Aceptado: 15/05/2020

Doi: https://dx.doi.org/10.6018/rmu/415541

Publicado bajo licencia CC BY-SA

\begin{abstract}
Resumen
En Inchola, caserío situado en la umbría de la Sierra de Carrascoy, se levantan los restos de una estructura defensiva medieval, llamada Torre de Inchola, y los de una antigua conducción hidráulica conocida como Caño del Barracón. En ambas edificaciones se desarrolla un variado repertorio de signos grabados sobre sus muros, entre los que predominan los que reproducen la forma de herradura. En este trabajo se describe la tipología de los grabados, proponiendo posibles líneas de interpretación histórica y una probable datación de los mismos en el contexto de los inicios de la Edad Moderna en el Reino de Murcia.
\end{abstract}

\section{Palabras clave}

Torre de Inchola, Caño del Barracón, grabados, herradura, canal, Alhama de Murcia.

\begin{abstract}
In Inchola, a hamlet located in the shaded areas of the Sierra de Carrascoy, we find the remains of a medieval defensive structure, called Torre de Inchola, and those of an old hydraulic conduction known as Caño del Barracón. There is a wide collection of signs engraved on the walls of both constructions. The signs reproducing horseshoe shapes predominate. This paper describes the typology of these engravings, proposing different lines of historical interpretation and a likely dating in the context of the beginnings of the Modern Age in the Kingdom of Murcia.
\end{abstract}

\section{Keywords}

Torre de Inchola, Caño del Barracón, engravings, horseshoe, water channel, Alhama de Murcia.

\footnotetext{
* Sociedad Murciana de Antropología (SOMA).Email: rabalgregorio61@gmail.com.

** Universidad de Alicante. Departamento de Geografía Humana. Email: gregorio.castejon@ua.es.
} 


\section{INTRODUCCIÓN}

El objetivo del presente trabajo es dar a conocer y contextualizar históricamente un conjunto de signos esculpidos, que ocupan parte de la superficie mural de dos antiguos elementos arquitectónicos diferentes en cuanto a su funcionalidad, aunque de idéntica relevancia como destacados bienes patrimoniales. Esto es, una atalaya defensiva, la Torre de Inchola, y una antigua conducción hidráulica que los lugareños denominan Caño del Barracón.

A los valores arquitectónicos, históricos y etnográficos que intrínsecamente atesoran ambos elementos, se une la originalidad de contar con una serie de grafitos históricos realizados en sus paredes, cuya tipología se documenta con este trabajo por primera vez en territorio murciano. De esta forma, los signos identificados y examinados constituyen una muestra especialmente relevante tanto por su indudable importancia e interés histórico, como por sumar un nuevo enclave al catálogo de grafías similares presentes en otros puntos del territorio peninsular.

En su mayoría son motivos clasificados bajo el término de herraduras, cuya representación, dotada desde sus inicios de reconocida significación simbólica, tiene sus primeros ejemplos en la Prehistoria, perviviendo posteriormente como modelo iconográfico hasta épocas moderna y contemporánea con otro tipo de funcionalidad o desprovista de ella, transformado en una mera reproducción de signos de diseño sencillo. ${ }^{1}$

Pese a las muestras de deterioro que presentan los muros donde se encuentran los grafitos, propias del paso del tiempo, ${ }^{2}$ la consistencia de la obra y el esmero aplicado en su acabado, especialmente perceptible en el

1 Esa sencillez permite contemplar la posibilidad de la representación de estos motivos en cualquier tiempo, sin necesidad de que exista relación de causalidad o de imitación respecto a representaciones similares pertenecientes a momentos históricos anteriores, debiendo abordar el estudio de estas grafías a partir de aspectos como el entorno, la tipología iconográfica de los signos representados y su asociación con algunos especialmente relevantes; los paralelos iconográficos, el soporte, entre otros aspectos (Gilotte y González, 2002, 260).

2 Parte de la canalización, concretamente el sector terminal más cercano a la balsa que almacenaba los caudales que discurrían por la infraestructura hidráulica soporte de los grabados, fue destruida durante procesos de roturación y aterrazamiento de la base del cerro donde se asientan la torre y el caño. Por esta razón, amplios tramos de canalización quedaron desplazados varios metros, trastocando su disposición y orientación originales, ocultando el muro frontal del caño, privándonos de la posibilidad de poder comprobar la presencia de grabados en este sector. 
muro de la conducción hidráulica, han permitido un más que aceptable estado de conservación de los mismos. A ello ha contribuido, sin duda, la técnica empleada para realizarlos, basada en el picado o repicado de la superficie parietal, generando trazos de cierta profundidad y amplitud, aparentemente poco modificados por la acción de los agentes medioambientales externos. Estas circunstancias técnicas han favorecido poder documentar detalladamente los grabados mediante calcos realizados directamente sobre ellos. La documentación gráfica de los signos de Inchola se completa con la realización de fotografías en distintos momentos del día, aprovechando la diferente incidencia de la luz solar sobre los muros. De este modo, se han podido apreciar detalles en la forma y factura de los motivos y descubrir signos que habían pasado desapercibidos en imágenes tomadas en otros instantes del día.

Completan la metodología llevada a cabo como fase previa al estudio que a continuación se presenta, la descripción de los motivos sectorizando el tramo de canalización donde se encuentran en segmentos de longitud variable en función del número y disposición de los signos; la medición de toda la infraestructura y de cada uno de los grabados; la elaboración de croquis con posicionamiento de cada uno de ellos en el contexto general de la estructura hidráulica y, por último, la georreferenciación del conjunto a partir de dispositivo GPS.

\section{ENCUADRE GEOGRÁFICO}

Las construcciones sobre las que se realizaron los grabados que se analizan, se localizan en el paraje de Torre de Inchola, al este del caserío de Los Ventorrillos $(1,2 \mathrm{~km})$ y al sur del caserío de Inchola $(1,8 \mathrm{~km})$, ambos asentamientos situados en los límites de la pedanía de La Costera, perteneciente al municipio de Alhama de Murcia y de cuya cabecera municipal dista apenas 9,5 km (Figura 1).

Tanto la obra hidráulica como la atalaya, se ubican en la margen derecha de la rambla llamada de la Tía Pereta (también denominada del Algarrobo, de la Cueva o del Barracón), cauce que drena parte del sector de umbría de la Sierra de Carrascoy (Figura 2). En concreto, en el lugar en que dicho barranco deja atrás las últimas elevaciones del citado relieve y se abre al valle del río Guadalentín, es decir, en la zona límite de contacto entre el piedemonte y las primeras estribaciones que dan inicio al área montuosa. Se trata de un espacio de clima mediterráneo semiárido, pese a la mayor humedad de este sector 


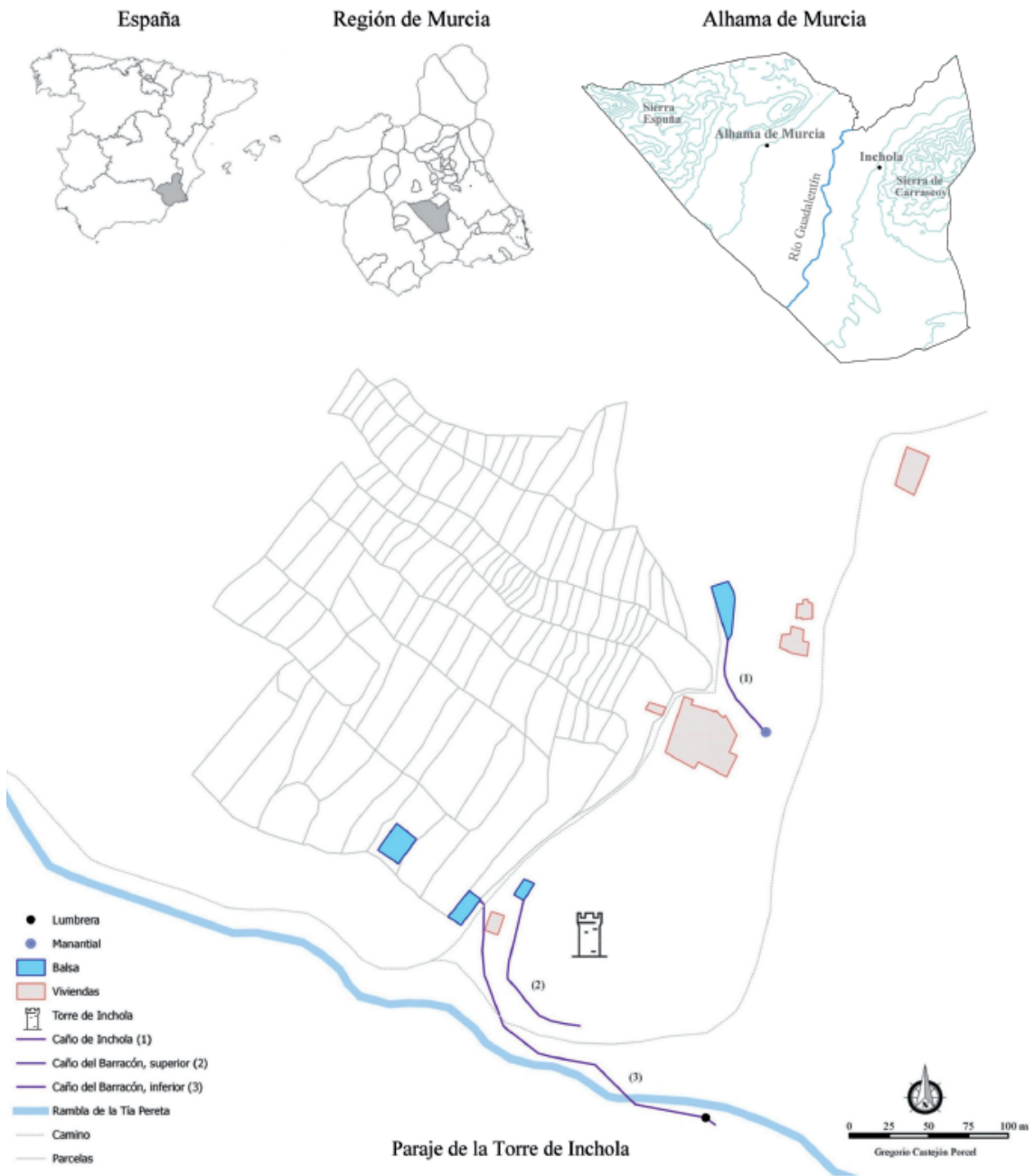

Figura 1. Contextualización geográfica de la Torre de Inchola y el Caño del Barracón (Elaboración propia).

de la sierra con respecto al área de solana, no solo por la orientación en relación al sol, sino también por el hecho de que las condiciones orográficas repercuten positivamente en que disfrute de un mayor volumen de precipitación media anual. 


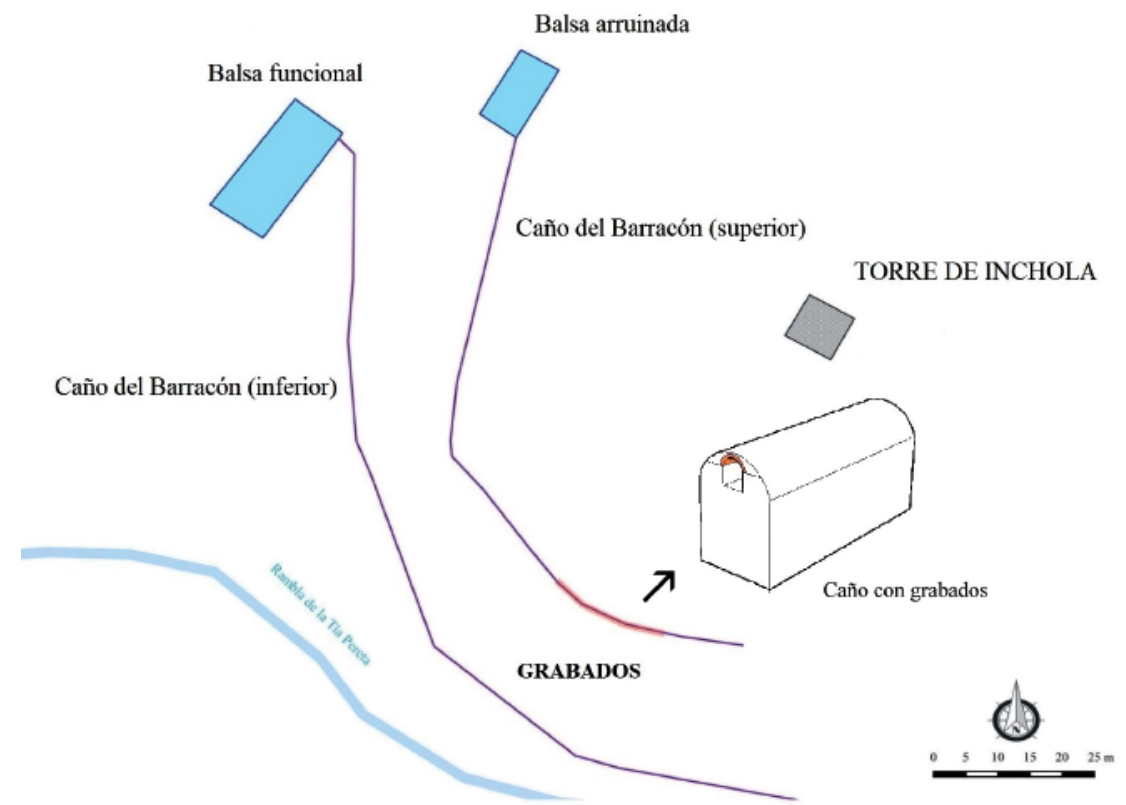

Figura 2. Elementos hidráulicos en torno a la Torre de Inchola.

A partir de la aldea y en dirección hacia el Guadalentín, el terrazgo presenta un uso casi exclusivamente agrícola, dedicado al cultivo de cítricos con presencia minoritaria de cultivo de uva de mesa, almendros y pequeñas parcelas de huerta en el entorno de las viviendas, aprovechando los caudales de agua que aún siguen manando de fuentes y minados situados a lo largo de este sector del piedemonte de Carrascoy. La relevancia de estos veneros en un medio de elevada carestía pluviométrica, se mantiene en el tiempo desde el mismo inicio de su dilatado aprovechamiento. La construcción de una amplia red de canalizaciones que parten desde los alumbramientos de aguas y discurren a lo largo de vertientes y laderas, ha permitido a los habitantes de la zona desplazar los caudales hasta varias balsas situadas en los alrededores de la Torre de Inchola, como también se hizo al otro lado de la sierra (Castejón y Rabal, 2018 y 2019). De esta forma, con estos aprovisionamientos más o menos estables, la población logró un indispensable recurso para cultivar espacios hasta ese momento incultos, o fuertemente condicionados a las lluvias estacionales. 


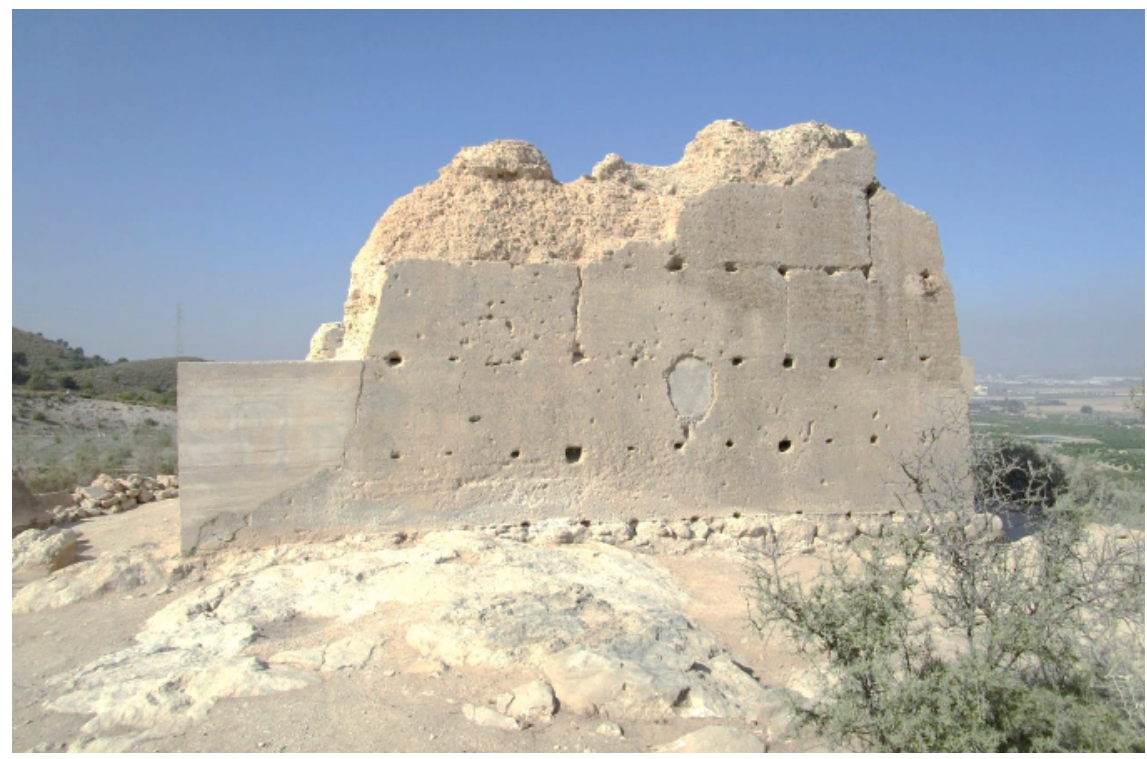

Figura 3. Torre de Inchola (muro Este).

Por lo que respecta a la estructura defensiva 3 (Figura3), esta se erigió en una pequeña elevación con el fin de aprovechar la diferencia de altura y garantizar así una posición favorable de vigilancia de la vega del curso fluvial del río Guadalentín, valle considerado como una excelente vía de comunicación natural hacia Granada y hacia Aragón (Baños, 2005: 133; Ramírez y Baños, 2005, 268). Es decir, en un punto estratégico con una visión amplia de la llanura, lo que permitía anticiparse con tiempo suficiente ante posibles ataques, garantizando además la libre comunicación con otras atalayas o fortalezas por medio de ahumadas y fuegos.

3 Junto con la fortaleza de Alhama, cuya mención primero como hisn y posteriormente como castillo se retrotrae a la primera mitad del siglo XII (Ramírez y Baños, 2005: 263), Inchola constituye una de las múltiples fortificaciones de características similares levantadas en los bordes de la llanura aluvial, cuya función primordial fue la salvaguarda del territorio fértil y de la trascendental vía de comunicación que unía Mursiya (Murcia) y Lurqa (Lorca). El complejo defensivo estaba formado por varias torres instaladas, en su mayoría, en las áreas de piedemonte de la Sierra de Carrascoy (Inchola y Comarza) y en Sierra Espuña (Azaraque), además de la Torre del Lomo y la del paraje de La Pita o del Cañarico, levantadas en pleno valle. 
De igual manera, la canalización objeto de análisis (figuras 4 y 5), al igual que otra situada a corta distancia pero a cota más baja que esta, se edificó en la margen derecha de la rambla que evacúa hacia el oeste las aguas de este sector de la vertiente norte de Carrascoy, ubicándose, en concreto, en el espacio baldío comprendido entre la Torre de Inchola y el cauce de la rambla del Barracón o de la Tía Pereta. De este modo, ambas siguen una dirección idéntica a la de la vertiente excavada al pie del relieve, una de las múltiples que drenan esta elevación que separa el Campo de Cartagena y los valles de los ríos Guadalentín y Segura, entre las que caben destacar la rambla de Peñas Blancas, al sur, y la rambla o barranco de Yncholete al norte, esta última en clara conexión con el caserío de Inchola.

A pesar de que la misma red de salvaguarda supone un claro testimonio de la inseguridad del entorno en determinados periodos de la historia medieval y moderna del antiguo Reino de Murcia, las condiciones geográficas del área propiciaron la explotación agrícola tanto del valle como de la costera montana del mismo. En el primer caso, en una dimensión mayor gracias a los caudales del río que lo surca, en el segundo, mediante recursos hídricos pun-

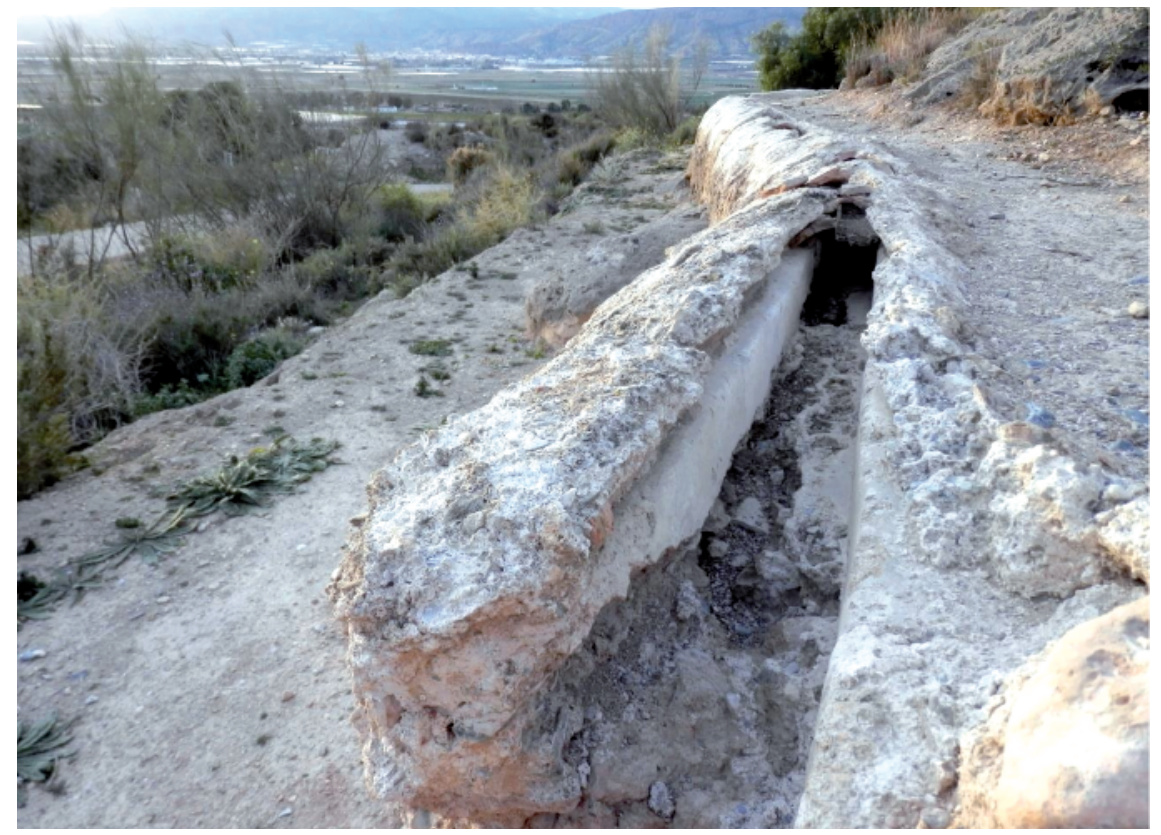

Figura 4. Caño del Barracón. Al fondo de la imagen el valle del Guadalentín y la población de Alhama de Murcia. 


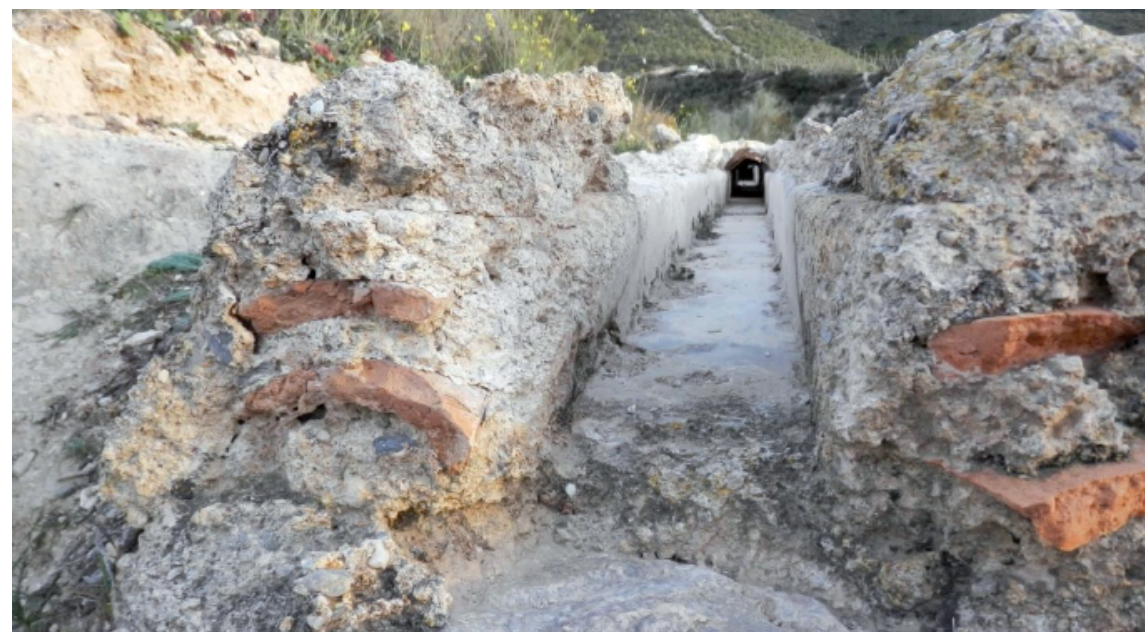

Figura 5. Caño del Barracón. Detalle de la estructura y perspectiva de la canalización.

tuales captados a partir de los veneros naturales del pie de la sierra o directamente del lecho de las ramblas que configuran la red de drenaje de este espacio, dando origen con ello a áreas irrigadas de menor tamaño que las del valle. En este sentido, resulta importante señalar que un buen número de las edificaciones defensivas emplazadas en el piedemonte de las sierras de Carrascoy y Cresta del Gallo, están asociadas a canalizaciones hidráulicas, hecho que demuestra la existencia de una clara intencionalidad de ubicar estas atalayas en puntos con disponibilidad de agua cercana.

Los volúmenes embalsados podían suponer no solo un bien de aprovisionamiento hídrico destinado a la irrigación de espacios de cultivo de amplitud variable, sino también el recurso necesario para establecer puntos de abrevadero para el ganado dada la importante actividad pastoril desarrollada en este entorno serrano, en el que la suma de la presencia de pastos y agua constituían una dupla vital para la actividad pecuaria, uno de los principales recursos económicos del entorno.

Sin duda, estos puestos vigías dotados de agua facilitaron el asentamiento de población en sus inmediaciones, tanto por la protección que ofrecían, como por las posibilidades vitales ya señaladas que brindaba la disponibilidad de agua. No obstante, Alhama de Murcia, Librilla, Sangonera, Alcantarilla y Murcia, supusieron el epicentro demográfico de este sector del valle del Guadalentín-Segura, mientras que en las zonas somontanas el hábitat, tanto en época musulmana como después de la conquista cristiana, debió tener un carácter diseminado. 
Además, por lo general un poblamiento mayor y más dinámico se ha congregado históricamente en el sector de la huerta ubicado en la falda de la Sierra de la Cresta del Gallo, en cuyo dinamismo poblacional ha jugado un papel destacado la importancia de su relación con la productiva Huerta de Murcia y la proximidad a la capital, primero del reino y posteriormente de la provincia. De este modo, se entiende que el territorio en el que se ubica la Torre de Inchola ha sido explotado con menor intensidad que el huertano, alimentado por las aguas del río Segura a su paso por la ciudad de Murcia, mediante la compleja y extensa red de acequias y azarbes. Además, ha constituido un área de poblamiento escaso, no tanto por la falta de recursos sino por la inseguridad inherente al hecho de ser un territorio próximo durante siglos a la frontera con el Reino de Granada, y por el aprovechamiento eminentemente ganadero al que se dedicó desde el siglo XIV.

\section{LAS CONSTRUCCIONES CON GRABADOS}

\subsection{La Torre de Inchola: cronología y funcionalidad}

Aun cuando la intencionalidad de este trabajo está lejos de formular o defender una datación precisa de la atalaya erigida en el paraje de Inchola, resulta necesario señalar las distintas fechas de construcción que se han atribuido a esta torre con el único propósito de contextualizar, en lo posible, el momento de edificación de los caños construidos en sus inmediaciones y los grabados presentes sobre una de las referidas conducciones.

En este sentido, en la Edad Media, en lo que hoy es la Región de Murcia, las torres vigías alcanzan su auge constructivo con la llegada de los almohades, concebidas como medio de afianzamiento de su poder ante el notable avance de las tropas cristianas sobre el territorio andalusí. ${ }^{4}$ No obstante, ningún

\footnotetext{
4 Sobre este tema, destacan aquellos trabajos que cuentan con referencias concretas a las torres ubicadas en el área de estudio, o cuyo análisis funcional coincide con el objetivo para el que fueron levantadas, sobre todo las ubicadas en los bordes de la fosa prelitoral ocupada por el río Guadalentín. Manzano Martínez, J. A. (1995). Arquitectura defensiva: delimitación de entornos y documentación histórica de 20 torres y castillos. Memorias de Arqueología, 10, 658-747; Martínez Rodríguez, A. (2011). La alcazaba de Lorca en época almohade. Tudmir: Revista del Museo Santa Clara, 2, 105-122; Ponce García, J. y Martínez Rodríguez, A. (1999). El castillo de Felí (Purias, Lorca) a partir de las últimas intervenciones arqueológicas. Clavis, 1, 9-36; Martínez Rodríguez, A. (1997). Las torres del campo de Lorca como complemento defensivo de una ciudad frontera. En Actas del Congreso la Frontera Oriental Nazarí como Sujeto Histórico (S.XIII-XVI). Lorca-Vera, 161-170.
} 
investigador ha atribuido la fecha de construcción del inmueble a esta época de control musulmán, hecho que, además, queda reforzado por la práctica ausencia de material cerámico islámico, tanto en la obra de la torre como en las inmediaciones de las conducciones hidráulicas próximas. Por contra, en distintas publicaciones, entre las que se encuentra la Memoria de Patrimonio 2003-2005 (López, 2005: 37), se hace constar que la fortificación se levantó en el siglo XIII, haciendo extensible el origen de la misma a un tiempo cercano al de otras estructuras defensivas similares ubicadas en el entorno del valle del Guadalentín, caso de las torres de Comarza, Azaraque, Lomo, Ascoy o Torreblanca.

De acuerdo con esto, la incorporación de Murcia a la corona castellana en 1243 tras el Tratado de Alcaraz, así como la toma de Lorca en 1244, propiciaron la necesidad de ejercer un férreo control del espacio ante los posibles ataques andalusíes o las propias revueltas de la población mudéjar residente en este espacio (como fue el caso de la acaecida entre 1264-1266), hecho que pudo provocar la edificación de parte del sistema de control del valle que comunicaba Murcia con Lorca.

Sin embargo, esta opinión difiere de la señalada por Navarro Suárez (1994, 17), quien sostiene que tanto Inchola como Comarza fueron mandadas edificar por Alfonso XI, hecho que de ser cierto llevaría a datar la construcción de las mismas en el siglo XIV, en un momento comprendido entre 1312 y 1350, periodo del reinado del referido monarca castellano, aunque este no asumiera plenamente el trono hasta 1325 . No se descartan cronologías aún más tardías para la torre, fechando la obra en la Edad Moderna, concretamente en el tránsito entre los siglos XV y XVI, coincidiendo con el periodo de consolidación de la ocupación cristiana del territorio tras la conquista de la Granada nazarí por los Reyes Católicos.

\subsection{El Caño del Barracón}

Se trata de una canalización que recorre toda la ladera oeste del cerro donde está situada la Torre de Inchola, si bien a día de hoy el punto de inicio de esta conducción resulta desconocido, pese a la intensa labor de búsqueda realizada en el entorno. De esta forma, no se puede determinar de dónde surgían los caudales que discurrían por ella hasta el receptáculo de almacenamiento, una balsa rectangular situada al pie del cerro de cuya estructura solo quedan los restos del muro sur. No obstante, es evidente que condujo agua, tanto por la lógica de su existencia, como por la presencia en el propio caño de concreciones calcáreas que confirman, sin lugar a dudas, este hecho. 


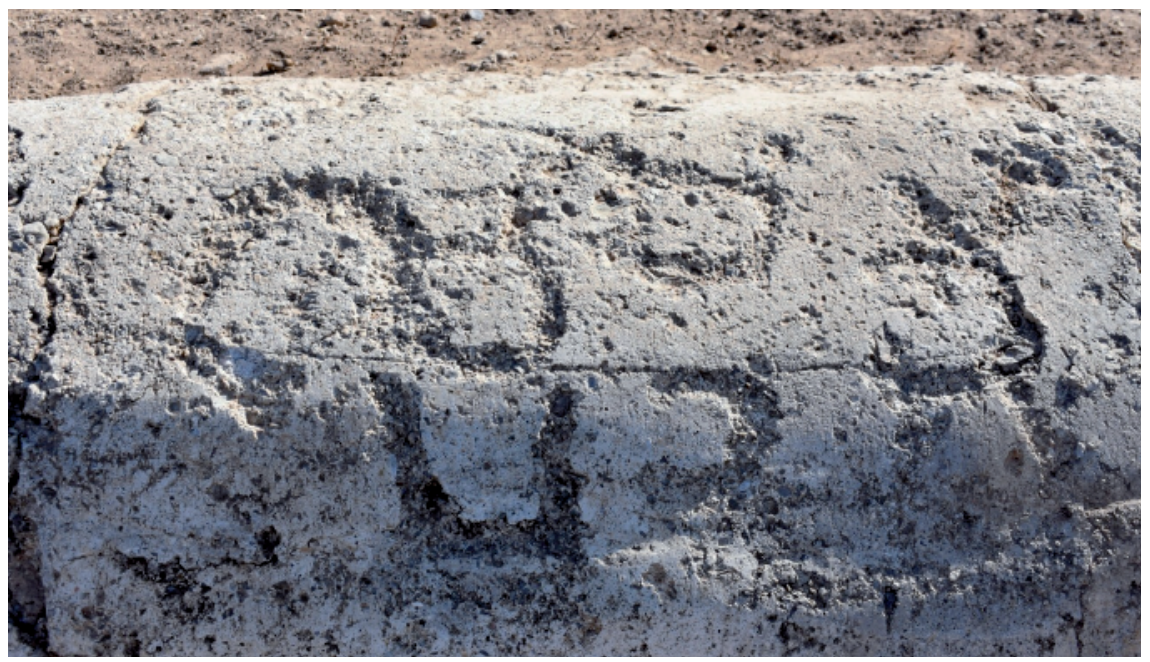

Figura 6. Caño del Barracón. Grupo de motivos con forma de herradura.

El caño se edificó utilizando mortero hidráulico muy fino realizado a base de arena, cal y agua, sobre obra de aparejo de mampostería de bloques de piedra del entorno, medianos e irregulares, unidos con argamasa. La parte visible en la actualidad ronda los $100 \mathrm{~m}$ de longitud, con una anchura de 0,50 $\mathrm{m}$, aunque se desconoce un tramo importante relacionado con el origen de las aguas conducidas por esta canalización.

Del análisis estructural y de los materiales empleados parece deducirse que hubo dos momentos o fases constructivas claramente diferenciadas por el conglomerante empleado en ambos casos. En una primera fase se debió ejecutar el propio canal, 5 mientras que en una fase posterior se llevó a cabo el abovedado del mismo. ${ }^{6}$ Pese al deterioro ocasionado por el paso del tiempo y por la acción directa del ser humano, la capa de argamasa que cubre y sella la conducción presenta un enlucido de aspecto bruñido, totalmente liso, que contrasta con paramentos murales de otras construcciones hidráulicas antiguas, algunas de ellas próximas al enclave de Inchola, en las que el cuidado y

5 Canalización de $14 \mathrm{~cm}$ de ancho por $11 \mathrm{~cm}$ de alto y muros de $12 \mathrm{~cm}$ de ancho a cada lado.

6 Para ello se utilizaron tejas cerámicas de unos $2 \mathrm{~cm}$ de grosor, $44 \mathrm{~cm}$ de largo y $18 \mathrm{~cm}$ de ancho en su lado mayor, imbricadas y posteriormente cubiertas con argamasa de cal y arena de grano grueso. Cabe destacar la utilización de fragmentos de tejas como elemento constructivo para alzar el perfil del recubrimiento sobre la parte superior del canal. 
esmero máximo se pone en la estanqueidad del espacio por donde debía discurrir el agua, como así sucede también en el canal de este sistema, y no tanto en los muros exteriores en los que se reduce la atención al acabado.

Sobre dicho enlucido exterior se realizaron los grafitos analizados en este trabajo (Figura 6), cuyo estudio y catalogación podría ofrecer datos interesantes acerca de la historia de esta canalización hidráulica, de la propia obra defensiva, así como de la ocupación y explotación histórica del entorno del paraje e incluso de la mentalidad de quienes lo habitaron.

\section{DESCRIPCIÓN DE LOS MOTIVOS}

Analizadas las edificaciones (defensiva e hidráulica) sobre las que se labraron los distintos signos, la tarea siguiente consiste en el estudio tipológico y expositivo del amplio conjunto de estos grafitos (Tabla 1), que como se puede apreciar (Figura 7) presentan distintas características morfológicas que en aras de la simplificación de su examen pueden agruparse, según su forma, en tres tipos: herraduras, motivos circulares y aquellos que tienden a la forma de la

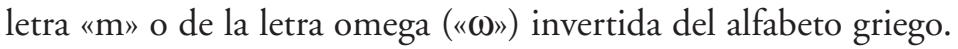

\subsection{Motivos con forma de herradura}

A su relevancia numérica en el contexto global de los grafitos de Inchola, se une su diversidad en lo que a forma y tamaño se refiere (Figura 8). En este sentido, cabe decir que los hay con el borde superior recto o curvo; con los extremos en ocasiones muy cerrados, pero también rectos o ligeramente abiertos; con ancho variable (medido en los extremos de los motivos) entre 5,0 y $15,5 \mathrm{~cm}$; y con alturas que oscilan entre los 6,0 y los $17,5 \mathrm{~cm}$. Sin embargo, el ancho del trazo de los motivos se mantiene de forma uniforme entre los 2,0 y los $3,0 \mathrm{~cm}$.

\subsection{Motivos circulares}

Los motivos circulares o anulares (Figura 9), algunos de ellos tendentes a la forma ovalada, presentan diámetros variables que van desde los 9,0 a los $15,5 \mathrm{~cm}$, tomando como referencia el borde externo del trazo, cuya anchura oscila, como en el resto de tipos iconográficos representados, entre los 2,0 y los $3,5 \mathrm{~cm}$. 


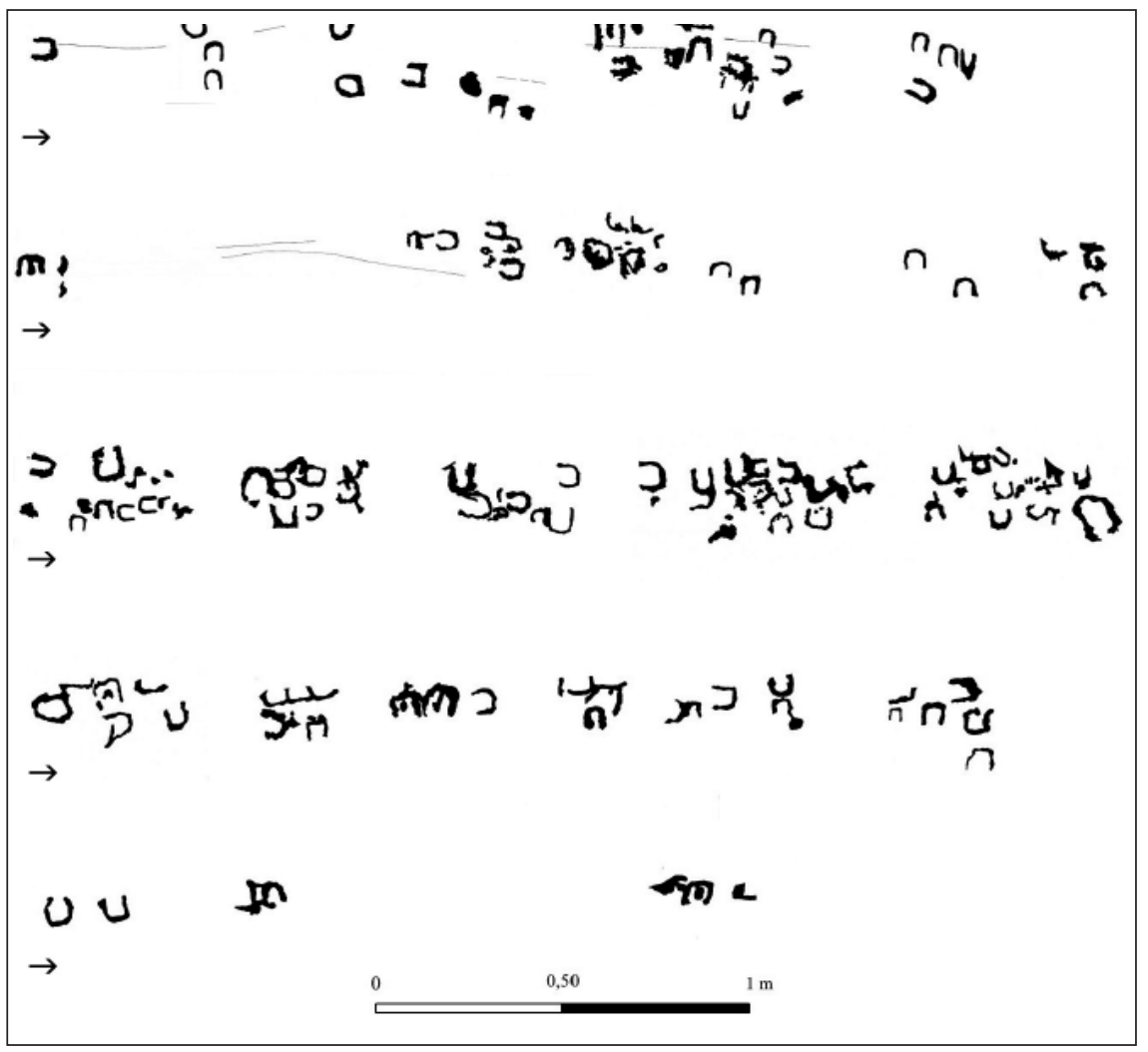

Figura 7. Conjunto de grabados del Caño del Barracón a partir de la digitalización de los calcos realizados.

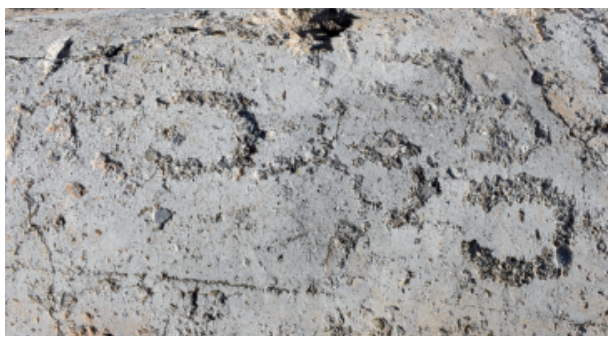

Figura 8. Motivos con forma de herradura sobre el Caño del Barracón.

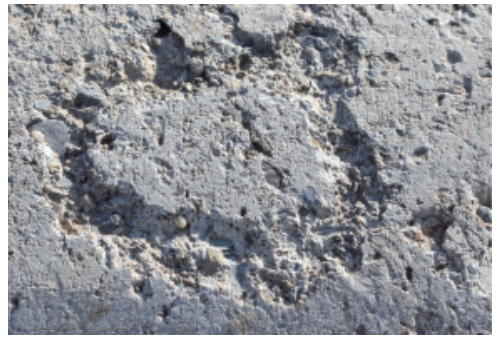

Figura 9. Motivo con forma ovalada. 


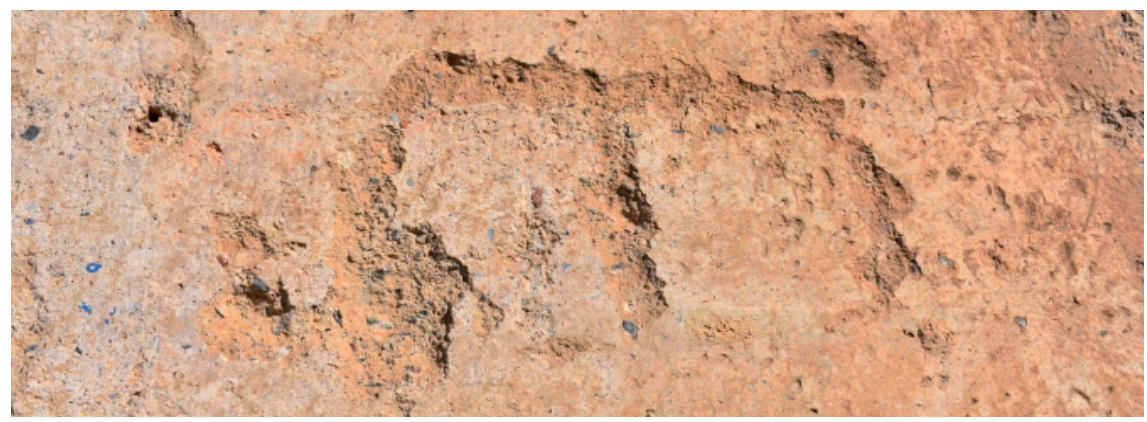

Figura 10. Muro de la Torre de Inchola donde se aprecia un motivo con forma de omega.

\subsection{Motivos con forma de «M» o semejantes a la omega griega}

Respecto a ellos, cabe destacar que podría ser el resultado de la unión de dos motivos con forma de herradura, al menos así parece deducirse de la observación de alguno de los motivos documentados con esa forma ${ }^{7}$ (Figura 10). Sus medidas oscilan, en lo que a abertura se refiere, entre 9 y $11 \mathrm{~cm}$; su altura también es variable y va de los 9,0 a los $11,5 \mathrm{~cm}$. Por lo que a la anchura del trazo se refiere, esta oscila entre 1,5 y $3,0 \mathrm{~cm}$, mostrando cierta uniformidad respecto a la anchura de trazo de otros motivos, un dato que podría aportar información respecto a la similitud de la herramienta o herramientas utilizadas, así como al momento en que fueron realizados los grafitos.

\section{DISTRIBUCIÓN DE LOS GRABADOS}

\subsection{Caño del Barracón}

A lo largo de un tramo de algo más de $20 \mathrm{~m}$ de esta conducción hidráulica, se distribuyen unos 162 grafitos realizados sobre la cubierta y el enluci-

\footnotetext{
7 Cressier $(1992,125)$, y Barrera y Cressier $(2003,713)$ hablan de «formas emparentadas con la letra griega omega, pero más estilizadas»; de "M estilizada», relacionándola, en este caso, con un símbolo mariano; o de «herraduras con trazo vertical interno». Tal vez dicho trazo sea la forma para reproducir la letra griega omega $(\omega)$, sobre todo cuando el trazo intermedio es más corto que los laterales que configuran habitualmente la forma iconográfica asociada a la herradura.
} 


\begin{tabular}{|lcc|}
\hline \multicolumn{1}{|c}{ TIPOLOGÍA } & CANTIDAD & PORCENTAIE SOBRE EL TOTAL DE GRABADOS \\
\hline Herraduras & 97 & $60 \%$ \\
Círculos, formas ovaladas & 12 & $7,0 \%$ \\
Sección de círculo, trazos angulosos... & 8 & $5,0 \%$ \\
Omegas, «M» & 7 & $4,3 \%$ \\
Grabados anulares & 8 & $5,0 \%$ \\
Trazos verticales & 4 & $2,5 \%$ \\
Motivos lineales & 10 & $6,2 \%$ \\
Figuras formadas a partir de la unión & 3 & $2,0 \%$ \\
lateral de dos herraduras & 13 & $8,0 \%$ \\
Indeterminados & & \\
\hline
\end{tabular}

Tabla 1. Análisis cuantitativo y estadístico de la tipología de los grabados de Inchola. Fuente: Elaboración propia.

do del muro que sustenta el caño (Tabla 1). Las señales dejadas en su superficie durante el proceso de realización de los signos, parecen indicar que se llevaron a cabo picando con una herramienta puntiaguda sobre la superficie seca. Se descarta, a priori, el uso de un tipo de utensilio de borde recto y afilado, más adecuado para realizar motivos de contornos rectilíneos, angulosos y alargados, cuya escasa presencia en Inchola contrasta con el aplastante predominio de motivos de contornos curvos y de reducida longitud.

Únicamente dos líneas horizontales paralelas que de forma discontinua recorren gran parte de la pared del caño, parecen haber sido realizadas hundiendo un objeto afilado sobre el enlucido aún fresco, tratándose, por tanto, de los únicos elementos incisos de todo el conjunto. De ser así, se trataría de los motivos más antiguos, asociados por tanto al momento en el que se dota de cubierta al caño y se cubre su muro exterior de un enlucido más consisten-

8 Quedan bajo esta categoría los motivos que no reproducen modelos iconográficos concretos e identificables. Además, cabe destacar la presencia de un gran número de señales y perforaciones de escaso diámetro y profundidad, distribuidas por toda la superficie del muro, fruto de impactos de objetos de extremo agudo, no contabilizados en el estudio de conjunto tratado en este artículo. 


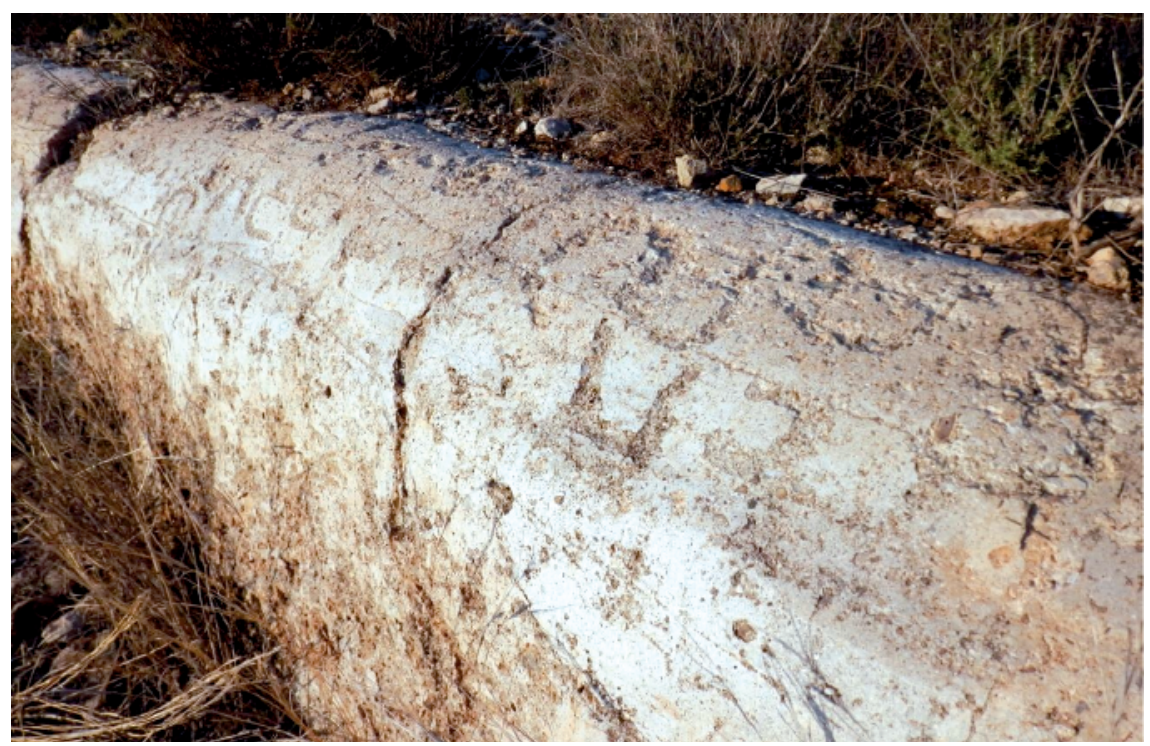

Figura. 11. Sector del Caño del Barracón con alta densidad de motivos.

te. Estas líneas parece que pudieron servir de marco o renglón a un buen número de las formas grabadas, especialmente aquellas que están más separadas entre sí y que manifiestan, aparentemente, una disposición más estructurada, más ordenada y lineal si la comparamos con los sectores del muro en los que los motivos son más numerosos y presentan una disposición más abigarrada y densa.

Como se ha señalado anteriormente, los grafitos con forma de herradura (Figura 11) constituyen el grupo más numeroso de todo el conjunto de signos presentes en Inchola, con un total de unos 97, lo que equivale, aproximadamente, al 60\% de los signos documentados. Un análisis más exhaustivo de este tipo iconográfico, permite advertir que predominan las formas que están dispuestas en horizontal (unas 36, alrededor del 24\% del total) y dentro de estas las que lo hacen con los extremos orientados hacia la izquierda (30, un $19 \%$ ), frente a las que los tienen orientados a la derecha (6 que equivalen a algo menos del $4 \%$ del total). La disposición en vertical o ligeramente inclinada, con la abertura hacia arriba o hacia abajo, aparece representada en 52 ocasiones, lo que equivale a un $34 \%$.

En su mayoría se distribuyen separados entre sí, aunque en aquellos sectores donde la densidad es mayor parecen estar unidos en posiciones variadas, siendo difícil establecer si dicha unión se produce por el contacto inevitable 
en secciones del muro con mayor profusión de signos, o si por el contrario al unirlos se pretendió generar formas más complejas de difícil interpretación desde un punto de vista figurativo, generando formas asociadas claramente con la grafía clásica de la letra griega omega. Tampoco parece descabellado pensar que, tal vez, lo que se quiso fue aprovechar parte del signo picado con anterioridad para economizar esfuerzos y tiempo, añadiendo solo algunas partes del nuevo.

Por otro lado, la disposición de los grafitos sobre el muro del caño no sigue, aparentemente, patrón alguno que pueda establecerse a partir de la observación directa de los mismos. No obstante, parecen distribuirse en buena medida en alineaciones que se ajustan a las líneas de desarrollo horizontal anteriormente citadas, formando grupos más o menos regulares, especialmente en la parte central del conjunto, distribuidos en tramos de aproximadamente un metro de longitud.

De acuerdo con esto, los signos aumentan en número hacia la mitad del caño conservado, un sector muy visible cuyo trazado se acomoda al contorno del cerro describiendo una ligera curva. En este punto los grafitos se juntan y yuxtaponen, generando a partir del diseño de herradura, como señalábamos con anterioridad, formas difícilmente asociables a cualquiera de las que configuran el catálogo de este tipo de manifestaciones gráficas realizado a partir de los estudios de otras estaciones peninsulares en las que aparecen.

\subsection{Torre de Inchola}

En el caso de los grafitos de la torre, estos se circunscriben exclusivamente a la cara interna de su muro Este. Están situados en el tercer cuerpo del mismo y se trata de varias herraduras, una omega, y una línea ligeramente ondulada que acaba en una muesca de forma romboidal, con una sucesión de unos 14 puntos grabados bajo ella (Figura12). Su interpretación resulta compleja al no contar con paralelos similares en otros puntos del país, aunque bien pudiera tratarse de algún tipo de línea de contabilidad, un tipo de grafito histórico muy frecuente con diferente significado según el edificio en el que aparezca. 


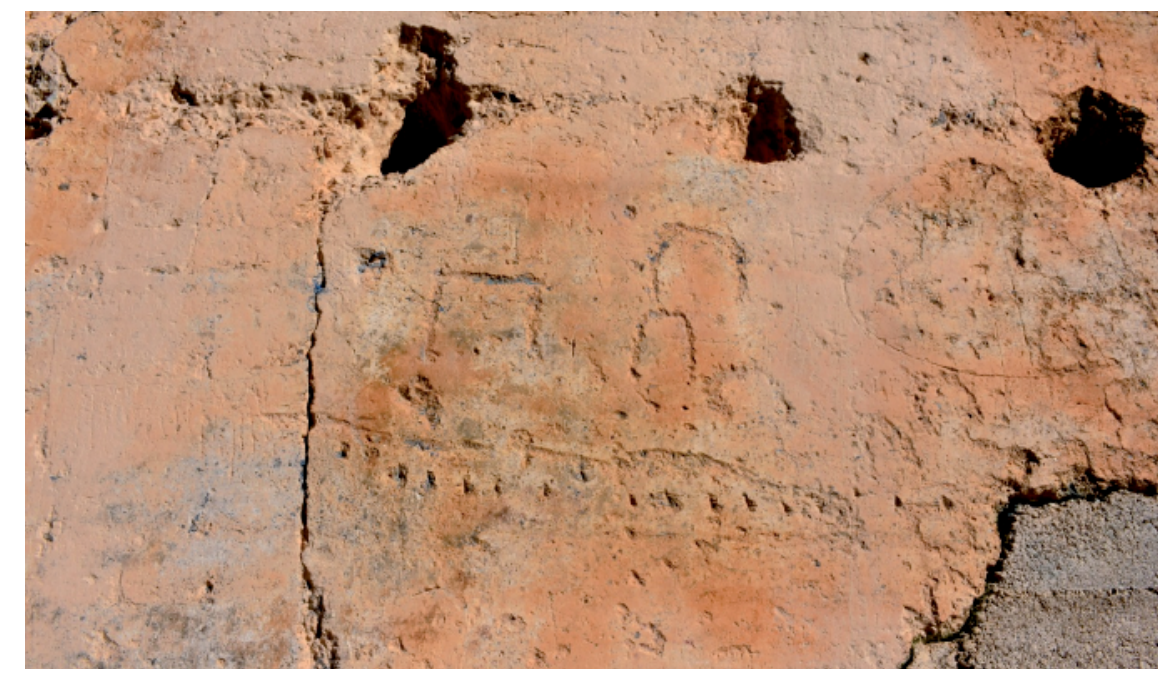

Figura. 12. Muro de la Torre de Inchola con herraduras y motivo alargado.

\section{PARALELISMOS}

Parece más que razonable establecer un paralelismo directo con grabados semejantes distribuidos en edificaciones de distintas localidades almerienses y granadinas (Cressier, 1992, Barrera y Cressier, 2003), ${ }^{9}$ sin olvidar la amplia difusión de este tipo de motivos en otras regiones españolas, especialmente del centro y norte del país. Entre las razones que avalan tal relación, podemos destacar las siguientes: la proximidad geográfica entre las tierras del sector oriental de Andalucía y el Reino de Murcia; las semejanzas técnicas e iconográficas que manifiestan los grabados de ambos territorios, sin duda el argumento más evidente; el hecho de encontrarse en construcciones defensivas y también en aquellas relacionadas con el manejo del agua, circunstancia posiblemente nada casual y de cierta relevancia a la hora de sustentar la relación entre los grabados andaluces y los analizados en este trabajo; el trasiego de población en los límites entre ambos territorios, largo tiempo convertidos en frontera insegura y peligrosa, prueba evidente de la existencia de relaciones de todo

${ }^{9}$ Cressier $(1992,141)$ les atribuye un origen histórico que los situaría entre el final de la Edad Media, posterior al siglo XV, y el inicio de la Edad Moderna, coincidiendo con el asentamiento de nuevos pobladores tras la derrota y expulsión de los moriscos. 
tipo desde la Baja Edad Media entre las poblaciones musulmanas del emirato nazarí de Granada y las comunidades mudéjares del reino de Murcia (Castillo, 2014, 68); ${ }^{10}$ así como la existencia de un sustrato cultural semejante, instalado tras la ocupación cristiana y reforzado con la reocupación del territorio una vez eliminada la amenaza granadina primero y resuelto después el problema morisco. En ese contexto, la ocupación cristiana trastoca intensamente las ideas y creencias de la población mudéjar existente en la zona, imponiendo nuevos valores que servirán de argumento esencial para justificar una de las interpretaciones planteadas respecto a la funcionalidad que en su momento pudieron tener estos símbolos esculpidos. ${ }^{11}$

Más lejana desde el punto de vista espacial, no tanto desde el iconográfico, queda la comparación de los grabados de Inchola con otros semejantes hallados en distintos lugares de la Península y fuera de ella, ${ }^{12}$ de fisonomía semejante y con datación cronológica que los sitúa también en la Edad Media e incluso en épocas Moderna y Contemporánea.

La lista es amplia y sigue incrementándose con cada nuevo hallazgo, abarcando la práctica totalidad del territorio español, lo cual plantea la posibilidad de que se trate de un fenómeno cuya difusión vaya pareja a la de otros motivos como los cruciformes (Gilotte y González, 2002: 260), sin olvidar la presencia de este tipo de motivos también en el Norte de África, así como en edificios medievales de determinadas áreas y comarcas de Francia.

10 Unas relaciones que debieron incrementarse con la relajación de la antigua frontera medieval tras la conquista de Granada en 1492 y la unión dinástica de las coronas de Aragón y Castilla, aunque posteriormente se vieron seriamente afectadas por la sublevación morisca de las Alpujarras y el levantamiento del barrio granadino del Albaicín acaecido en 1568 (Castillo, 2014, 69).

11 Para Cressier (1992, 142), la funcionalidad simbólica parece más que probable. Herraduras, omegas y cruciformes, serían elementos de exorcismo popular cristiano aplicados en edificios «impuros» de época andalusí. En el caso de los aljibes, los grabados cumplen, al parecer, el cometido de anular la función primitiva del edificio, lo cual permite establecer una atribución plenamente cristiana. Para ello, sobre los muros de estas cisternas se grabaron cruciformes, solos o asociados con herraduras y omegas, combinados entre sí para formar figuras de carácter antropomorfo.

12 Barrera y Cressier $(2003,714-715)$ ponen de manifiesto la existencia de paralelos para este tipo de grabados en el vecino Marruecos, concretamente en el Cabo Cantin y en el valle de Dadés, citando a Herber y Gattefosse respectivamente, fechados por la tradición oral como de época medieval. Las herraduras marroquíes, grabados conocidos como "pezuña de equino», muestran continuidad hasta principios del siglo XX, dentro de un ámbito cultural islámico. 


\section{PROPUESTAS DE INTERPRETACIÓN}

Sin duda, la motivación que sustenta la decisión de realizarlos, así como el significado y la funcionalidad que al parecer tuvieron, son algunas de las cuestiones más complejas y difíciles de determinar en el estudio y análisis de los grabados murales y parietales, sea cual sea el momento en que estos fueron realizados. Plantear tales cuestiones, lleva implícita la presunción de que el sentido de estas manifestaciones culturales va más allá del mero acto lúdico de plasmar motivos diversos sobre la piedra o sobre la superficie de un muro solo por distracción o como modo de entretener el tiempo. ${ }^{13}$

Así, se entiende que este tipo de expresiones gráficas son parte de códigos de comunicación, lenguajes colectivos que transmiten ideas, creencias, sentimientos, inquietudes, acontecimientos, etc., relacionados con el entorno más cercano de quienes los hicieron. De este modo, fueron utilizados para comunicar mensajes de carácter simbólico que deben trascender y perdurar en el tiempo, dirigidos a las comunidades campesinas (Fernández y Lamalfa, $2005,265)$, grupos sociales poco conocidos y con escasa presencia en las fuentes documentales escritas.

Para las formas iconográficas agrupadas bajo el término «herraduras», las interpretaciones han sido numerosas y dispares, ${ }^{14}$ semejantes en algunos casos a las formuladas para explicar los ejemplos de esta tipología de épocas pre y

13 Una de las interpretaciones de las que se hacen eco Barrera y Cressier $(2003,718)$, formulada en su día por Gattefosse $(1933,63)$ y Ruhlmann $(1934,63)$. Ambos autores señalan que la realización de los grabados es una actividad de pasatiempo de pastores, circunstancia o intención documentada en Marruecos. Para España, son pocos los estudios que se han ocupado de un modo específico de la realización de grafitos por parte de este colectivo profesional, caracterizado por su secular movilidad espacial. En este sentido, caben destacar los trabajos de Jabato (2012) para Extremadura, y el de Líbano (2016-2017, 155-169) para un sector de la Sierra de la Demanda burgalesa.

14 Entre otras, caben destacar aquellas funciones relacionadas con la compartimentación del territorio, considerando que se trata de marcadores de la propiedad concebidos a modo de símbolos de término, función para la cual también se han utilizado motivos cruciformes hasta épocas recientes. Se trataría, en este sentido, de señales que manifiestan sobre el terreno el reparto de tierras o el deslinde de ámbitos territoriales pertenecientes a entidades locales o administrativas distintas, o bien hitos delimitadores entre áreas de uso y aprovechamiento diferenciado en virtud de sus características naturales, separando áreas ganaderas y de pastos en zonas de montaña, de áreas de aprovechamiento agrícola (Fernández y Lamalfa, 2005, 266).

Por otra parte, también se han interpretado como señal y advertencia a posibles usuarios acerca de qué tipo de ganado debía abrevar en la infraestructuras hidráulicas 
protohistóricas, sobre los que la tradición historiográfica española se ha ocupado de una forma continuada y extensa, no así para los medievales, modernos y contemporáneos, ${ }^{15}$ cuyo protagonismo en la historia de la investigación ha sido menor, eclipsado por el interés temprano despertado hacia el arte rupestre prehistórico.

Por tanto, la presencia de grafitos grabados en las construcciones de Inchola, su disposición y localización concreta sobre ellas, plantea interrogantes acerca de su funcionalidad que no puede ir separada ni del soporte sobre el que se realizaron, ni del contexto geográfico y arqueológico en el que se encuentran, ni tampoco de los avatares y acontecimientos históricos y socioeconómicos, bajomedievales y modernos, que tuvieron por escenario las tierras del Sureste peninsular.

Sin embargo, la falta de datos concluyentes de carácter material asociados a un contexto arqueológico bien definido; la ausencia de paralelos a nivel regional, lo cual limita la posibilidad de relación o paralelismo fiable únicamente a los ejemplos andaluces, hace que el marco interpretativo sea una formulación meramente hipotética en virtud de los datos disponibles hasta ahora.

La primera de las hipótesis considera más que probable la relación de los grabados de Inchola con el mundo pastoril y ganadero, coincidiendo con el proceso mediante el cual la ganadería se convierte en la actividad económica

que cuentan con este tipo de signos (Bailón-Moreno, 2008). De acuerdo con esto, la presencia de herraduras indicaría, en este caso, que el recurso estaría destinado al ganado caballar, de vital importancia como fuerza de trabajo y transporte, y no a los rebaños de ganado ovino que por su número podrían agotar el agua si se les permitiera acceder a diario a ella. Una interpretación incorporada a la descripción y estudio del llamado aljibe del Llano (Benimar, Almería), con referencia expresa a su cristianización en 1500 grabando varias cruces en la parte alta e interior del citado receptáculo.

Por último, son numerosísimos los ejemplos en los que la tradición popular, bajo el formato de leyendas y cuentos de tradición oral, ha convertido los grabados con forma de herradura en marcas dejadas por el caballo o la mula de un personaje sagrado (fundamentalmente Santiago, la Virgen o algún santo), o legendario (sobre todo el Cid o el héroe francés Roldán). Un buen estudio al respecto fue el realizado en su día por Antón Erkoreka en el territorio de la comunidad autónoma vasca, titulado Catálogo de «hueIlas» de personajes míticos en Euskal Herria. Munibe (Antropología-Arqueología), 47, 227252.

15 Gómez Barreda $(1993,445)$ señaló incluso que este tipo de grafitos fue un material frecuentemente despreciado al que se le privó inicialmente de la atención y estudio necesarios, sin considerar la continuidad que este tipo de motivos representan respecto a modelos cuyo recorrido histórico puede remontarse hasta época prehistórica, perdurando en el tiempo como ejemplos de una tradición artística protagonizada por colectivos, entre los que se encuentran los pastores. 
predominante en el Reino de Murcia, ${ }^{16}$ del mismo modo que lo era en el de Castilla, asociándose a dicho proceso no solo la ampliación de dehesas ${ }^{17} \mathrm{y}$ terrenos dedicados al pastoreo de ganados locales y trashumantes, sino también la consolidación de grupos de élite social vinculados con la propiedad de pastos y ganados.

Es en ese contexto, consolidado en el siglo XIV, en el que se produce a finales del siglo XV la pugna entre los concejos por ampliar y acotar sus dehesas, y que dio lugar a la intervención de jueces de término designados para dirimir disputas entre ellos o entre el concejo de Murcia y algunos miembros de la élite local dominante (Martínez, 1988, 112). Para el caso objeto de estudio, resulta de especial relevancia que sea el de Alhama de Murcia uno de esos concejos afectados por la reordenación de las condiciones de aprovechamiento de su espacio ganadero, y que lo haga precisamente hacia el piedemonte de la sierra de Carrascoy, afectando al entorno de Inchola y el contiguo barranco de Incholete, dos lugares con presencia constante de agua. ${ }^{18}$ Más tarde,

16 Una circunstancia, según Molina y Jiménez $(1996,55)$, propia de un territorio de frontera en el que la importancia económica de la ganadería resulta esencial en un territorio sometido a un fuerte proceso de despoblación que conlleva, entre otras consecuencias, el abandono de espacios de cultivo que se convierten en amplias extensiones de pastizal y terrenos devueltos a un estado seminatural o silvestre.

17 Una tendencia aplicada, tras la desaparición del peligro procedente de la frontera granadina, sobre pastos comunes, practicada en apretada competencia por concejos en expansión, poseedores de ganados cada vez más numerosos (Martínez, 1998, 111). En el caso de Alhama de Murcia, villa perteneciente al señorío de los Fajardo desde 1387, la fijación de su espacio ganadero debió contemplar la ampliación del mismo hacia el piedemonte de Carrascoy, área en la que se encuentra el entorno de Inchola, considerando la posibilidad de un mayor uso agrario en áreas próximas al Guadalentín, a pesar de la conversión en pastizales de las áreas despobladas a partir del siglo XIII. Esta circunstancia, estrechamente ligada al abandono del medio rural y a la concentración de la población en núcleos fortificados que ven aumentar su protagonismo, como en el caso de Alhama, resulta especialmente relevante en el Valle del Guadalentín, convertido en una de las zonas más despobladas del Reino de Murcia (Baños y Ramírez, 1997, 374).

18 El proceso de ampliación hacia la sierra de Carrascoy, estudiado y representado cartográficamente por Martínez (1988, 33-34), cuenta con la llamada «Punta de Inchola», lugar de herbaje de uso común, y el contiguo barranco de Incholete, como hitos geográficos tomados como referentes en la nueva delimitación del área de pastos abordada en el pleito entre el concejo de Murcia y el de Alhama, en la que intervino, a finales del siglo XV según el citado estudio, el juez de término Luis Pérez de Palencia. Un área con abundancia de agua, como dan fe las conducciones, minados y balsas existentes, de interés para los ganaderos del concejo murciano que ven ratificado, a partir de la sentencia del citado magistrado, su derecho a llevar sus ganados a un área de pastos de carácter comunal desde antiguo. 
entre mediados y finales del siglo XVI, el pleito entre los vecinos de Alhama y el señor de los Vélez vuelve a poner de manifiesto, entre otros aspectos, los problemas relacionados con el uso, disfrute y rentabilidad económica de las dehesas de la villa, formando parte del memorial de agravios presentado por los vecinos de Alhama en su pleito con Luis Fajardo de la Cueva, segundo marqués de los Vélez. ${ }^{19}$ En el momento de interposición del pleito, Inchola junto con la contigua Comarza eran dos de los millares con que contaba Alhama, prueba evidente de la importancia como área tradicional de pastos de la franja de terreno longitudinal de transición entre las laderas de Carrascoy y la vega del Guadalentín. ${ }^{20}$

Ambas circunstancias históricas podrían ser la base sobre la que sustentar la relación de los grabados de Inchola con señales de término destinadas a delimitar un espacio en disputa, apetecible no solo por su riqueza en pastos y agua, sino también por la cercanía a la vía de comunicación del Guadalentín, insegura hasta la conquista de Granada al padecer las consecuencias de la actividad bélica fronteriza (Baños y Ramírez, 1997, 379), pero de vital importancia en la configuración y articulación territorial del señorío de los Fajardo (Martínez, 1988, 114).

Por otro lado, no se descarta la posibilidad de una función simbólica para los grafitos que se analizan, otorgándoles un carácter protector semejante al desplegado en tierras almerienses y granadinas en las que se usaron. Sin embargo, la ausencia en Inchola de motivos cruciformes, abundantes en las edificaciones andalusíes de Almería y Granada compartiendo espacio con herraduras y omegas, parece reducir, a priori, la posibilidad de dicha funcionalidad, aunque el resto de motivos iconográficos coincida con los andaluces

19 En el estudio de dicho pleito realizado por Mozas y Vilar (1977, 39-41), se habla de «ocupación y arrendamiento indebidos» de la dehesa boyal del concejo destinada a la provisión de carne, y de «incautación» de la dehesa concejil proveedora de pastos para el ganado mayor, «bestias de montura, albarda y tracción». A los puntos señalados, habría que añadir la apropiación por parte del marqués de «tierras, montes, prados y abrevaderos de propiedad comunal», cuyo uso por el vecindario se ve condicionado al pago de determinados tributos. Para ambos autores, los tres aspectos mencionados deben entenderse como ejemplos de «derechos de índole netamente territorial» relacionados «con una hipotética vinculación solariega del territorio del señorío a su titular».

20 En el apéndice documental manejado por Mozas y Vilar (1977, 51-69) se mencionan hasta trece millares sobre los que el señorío de los Vélez venía ejerciendo un uso exclusivo, aun tratándose de espacios públicos de uso y disfrute de todo el vecindario de la villa. Una apropiación de bienes comunales, pastos y recursos hídricos, que no es exclusiva de la familia Fajardo, señores de Alhama, sino que se enmarca en un proceso del que participan concejos controlados firmemente por sus oligarquías locales (Hernández y Jiménez, 1996, 179 y 184). 
para los cuales la función apotropaica o protectora parece estar plenamente aceptada. Si a pesar de tan significada ausencia iconográfica existió alguna intención simbólica o protectora en los signos de Inchola, esta habría que relacionarla, probablemente, con el intenso proceso de abandono documentado en toda la zona desde mediados del siglo XIII, que pudo afectar al caño donde se encuentran la mayoría de los grafitos, así como a asentamientos del entorno que se convierten en despoblados sin continuidad de hábitat a partir del tercer cuarto del siglo XIII (Baños y Ramírez, 1997, 376).

No obstante, resulta difícil admitir que se prescinda de recursos hídricos permanentes postergando al olvido una infraestructura hidráulica de estas características, cuya planificación, ejecución y mantenimiento se aparta de la idea de provisionalidad asociada a un uso inmediato del recurso o circunscrito a un breve periodo de tiempo. Si en algún momento se interrumpió la funcionalidad del sistema hidráulico, esta se recuperó con la llegada de nuevos pobladores, procediendo a su reacondicionamiento arquitectónico (momento en el que, posiblemente, se dotó de cubierta al canal y se reforzó su muro lateral) para atender las necesidades de agua de los nuevos ocupantes del territorio.

\section{CRONOLOGÍA}

La forma de herradura constituye un tipo de grabado que se ha repetido a lo largo del tiempo, relacionándolo inicialmente y de un modo más concreto con la Edad del Bronce y el fenómeno del megalitismo. No obstante, pese a ser esta la cronología más repetida, se ha puesto de manifiesto la posibilidad de una cronología que vincula con la Edad del Hierro muchos de los lugares que cuentan con este tipo de representaciones, incorporando nuevos elementos iconográficos a los ya existentes con diseños más rudos y toscos, cuya pervivencia se prolonga hasta la Edad Media (Gómez-Barrera, 1993, 434).

En España, al menos para las estaciones del Noroeste y la Meseta, estos conjuntos serían sometidos a un redibujo o redefinición en época histórica por parte de la población cristiana que ampliará el repertorio iconográfico añadiendo motivos cruciformes a los preexistentes, para purificar lugares considerados como paganos según los postulados de la religión dominante. ${ }^{21}$

21 Amplia relación de lugares en www. diariodeleon.es, donde se señalan los casos de los grabados cristianizados de la Cabrera, así como la presencia de herraduras entre los petroglifos de Peñamartín, Chana de Somoza, Sopeña de Carneros, Pico Berrubia, entre otros. También en Portugal, donde muchas piedras con herraduras, pertenecientes al III milenio a. C., fueron cristianizadas mediante la incorporación de cruciformes (Cardoso, 2016, 62). 
En el caso de la Andalucía oriental, según apuntaron en su día Cressier (1992), y Barrera y Cressier (2003), los signos realizados sobre los muros de edificios islámicos en la provincia de Almería o los picados sobre roca, implican una datación de época histórica, andalusí o posterior a la conquista cristiana. En el caso de los aljibes, la presencia de este tipo de motivos junto con cruciformes, tiene la finalidad de anular la función primitiva del edificio, lo cual permite establecer una atribución plenamente cristiana que llevaría su cronología desde finales del siglo XV hasta el siglo XVII.

Para el caso de Inchola, la hipótesis acerca de una probable datación de los grabados ha de considerar, entre otros aspectos, la sucesión de acontecimientos históricos acaecidos en el Reino de Murcia tras su incorporación a la corona castellana a partir del siglo XIII, así como los cambios sociopolíticos y económicos que se produjeron a partir de ese momento, sin olvidar la impronta psicológica que supuso, por un lado, ser tierra de frontera y, por otro, mantener importantes contingentes de población mudéjar-morisca, de lealtad frecuentemente puesta en tela de juicio, ${ }^{22}$ hasta el decreto de expulsión de los moriscos de 1609.

Sabido es que para el valle del Guadalentín, y por extensión para toda la Región de Murcia, la documentación arqueológica disponible constata la presencia de alquerías andalusíes diseminadas, aprovechando los pastos existentes, la presencia de recursos hídricos permanentes y de tierras aptas para el cultivo distribuidas en la franja de transición entre el piedemonte serrano y el feraz valle, factores determinantes para el asentamiento estable de población en la zona hasta el siglo XIII (Ramírez y Baños, 1997). Del mismo modo, se ha puesto de manifiesto que es a partir de mediados de esa centuria cuando se produce un abandono generalizado de la población que busca tras los muros de las fortalezas la seguridad repetidamente amenazada por las incursiones procedentes del vecino reino de Granada, sin que resulte fácil precisar si dicho abandono demográfico fue total o hubo continuidad de poblamiento mudéjar en el entorno en fechas posteriores a la ocupación cristiana, pese

22 Actitud puesta de manifiesto en forma de recelos y cierta, aunque tal vez infundada, sensación de miedo colectivo derivado, en parte, de la situación del Reino de Murcia a caballo entre las populosas poblaciones moriscas de Valencia, Granada y Almería, que en el caso de Murcia dieron lugar no solo a un abierto rechazo en las inmediaciones de la ciudad, sino también a situaciones de acoso y hostigamiento por parte de la población cristiana hacia poblaciones moriscas del valle de Ricote y hacia otras residentes en territorios administrados por órdenes militares, como es el caso de Pliego, por parte de vecinos de Mula, villa perteneciente al marquesado de los Vélez (Castillo, 2014, 77). 
a la inseguridad que suponía encontrarse en una zona tan expuesta y próxima a la frontera occidental del reino. Para el área de estudio hisn como los de Alhama o Librilla ven consolidar su protagonismo como núcleos demográficos de entidad frente a un entorno casi o totalmente despoblado, manifestando en la centuria siguiente un crecimiento poblacional atestiguado por censos y registros parroquiales (Lemeunier, 2004, 89), paralelo al desarrollo de instituciones locales de gobierno tras los muros de las fortalezas concebidas como espacios seguros.

Una aproximación cronológica establecida en base a la funcionalidad que a lo largo de la historia se ha otorgado a este tipo de signos, utilizados como señales de término, de demarcación territorial, de deslinde o de delimitación de zonas de aprovechamiento pecuario, acompañando a otro tipo de motivos, especialmente a los cruciformes, situaría su origen incluso en el siglo XVI23 (Fernández y Lamalfa, 2005, 259), momento a partir del cual los grabados con forma de herradura cumplieron con esa función. De igual modo, ofrecen una cronología semejante aquellos motivos con forma de herradura que se añaden a otros preexistentes en edificaciones de carácter defensivo y también de almacenamiento de agua, una circunstancia que bien pudo repetirse más tarde, manteniendo un uso meramente gráfico y desprovisto de cualquier otra significación, a modo de repetición decorativa atemporal de formas iconográficas sencillas de origen remoto.

Para el caso de Inchola, la realización de sus grafitos, sea cual sea la funcionalidad que se les atribuya, habría que establecerla en el contexto de la dinámica demográfica que experimentan las tierras del Sureste a partir del siglo XV, caracterizada por la reocupación del territorio, pero también en relación con la revuelta morisca de Las Alpujarras (siglo XVI) y la implicación de huestes murcianas en la sofocación de la misma, o asociadas con posterioridad a la expulsión de los moriscos del Reino de Murcia (siglo XVII).

En este sentido, se podría decir que un contexto cronológico plausible, establecido de manera amplia, los situaría entre los siglos XV y XVII, coincidiendo con algunos de los hechos acaecidos en ese convulso periodo que se inaugura con visos de futura seguridad para los territorios de la frontera, o próximos a ella, tras la caída de Granada. En consonancia con esto, no hay que olvidar la contribución de soldados del Reino de Murcia en la defensa de

\footnotetext{
23 Siglo en el que, entre otros motivos, se añaden herraduras en los paneles de grabados de los aljibes del castillo de Monsalud en Extremadura (Gilotte y González, 2002, 268).
} 
dicha frontera, como tampoco hay que pasar por alto la presencia de los mismos en la sublevación morisca de 1568, capitaneados por Luis Fajardo, segundo Marqués de Los Vélez, en el ejercicio de sus atribuciones como capitán general y Adelantado Mayor del Reino de Castilla. Su ejército, contingente de hombres reclutados en las poblaciones de su señorío, deambuló por tierras almerienses (Castillo, 2014, 70), participando con éxito en la segunda batalla de Berja, para establecerse posteriormente y durante un tiempo en la localidad de Adra (Castillo, 2014, 71-72).

La relevancia del sector almeriense en el que se ubican las localidades de Adra y Berja, radica en el hecho de tratarse de la zona donde se encuentran el grueso de edificios musulmanes que presentan grafitos, especialmente aljibes, que hipotéticamente pudieron servir de modelo a un anónimo autor de las herraduras de Inchola de vuelta a su tierra de origen, por lo que no se puede descartar la posibilidad de un conocimiento directo de los motivos reproducidos en Inchola a partir de la observación in situ de los existentes en territorio andaluz. Quién o quiénes los realizaron, pudieron ser conocedores de su existencia y de su uso en momentos coincidentes con la conquista de Granada, con la sofocación de la revuelta de las Alpujarras ${ }^{24}$ e incluso con la expulsión de los moriscos, pudiendo haber sido realizados tanto por imitación, como por una atribución simbólica semejante aplicada en ambos casos con el mismo propósito.

\section{CONCLUSIONES}

La documentación y estudio de los grabados del entorno de Inchola, entre los que destacan por su número los que se asemejan a la forma de herradura y por su singularidad aquellos que tienden a un trazo emparentado con la letra omega del alfabeto griego, permite incorporar la Región de Murcia al conjunto de territorios de la Península ibérica donde este tipo de signos, bien en solitario o combinados con motivos cruciformes, se han documentando a lo largo de las últimas décadas en el contexto del estudio de las distintas manifestaciones del arte rupestre.

24 Presencia de contingentes y recursos (alimentos y animales) mandados reclutar y hacer acopio, respectivamente, por los Reyes Católicos para sofocar la rebelión morisca de la Alpujarra, participando en el cerco de Velefique. Contingentes que fueron reclutados en Murcia y en Lorca de camino hacia Tabernas (Abellán Pérez, 1979, 28). 
Resulta significativa la presencia de este tipo de grafitos en una atalaya defensiva y en una conducción hidráulica, cuya funcionalidad está relacionada con las edificaciones almerienses y granadinas que acogen esta clase de grabados, reproduciendo casi miméticamente gran parte del repertorio iconográfico descrito y estudiado en su día en Andalucía oriental, a excepción de los cruciformes.

Se desconoce quiénes fueron sus autores. Una de las líneas propuestas acerca de la autoría de este tipo de manifestaciones en otros lugares de España, señala que han sido los pastores quienes, a lo largo de la historia y hasta fechas recientes, han marcado su presencia en el territorio sobre piedras y muros, al menos mientras estuvo activa un tipo de ganadería basada en desplazamientos temporales del ganado a larga distancia, o en la permanencia prolongada de los animales en sus zonas habituales de pasto durante el día. Una práctica de carácter gráfico-pictórico practicada por miembros de este colectivo no solo en España, de la cual poco se ha estudiado hasta el momento, sino también en otros puntos de Europa, como así se demuestra en el extraordinario conjunto de Pizancae en el Valle de Fiemme (Trentino, Italia).

En relación a su funcionalidad, resulta difícil establecer qué papel debieron jugar en su día los grabados de Inchola. Pudieron servir de marcas relacionadas con la actividad ganadera, como elementos de señalización de áreas de pasto en un contexto geográfico en el que cobra pujanza la actividad ganadera y por el que no dudan en enfrentarse los concejos y las elites locales deseosas de acrecentar su dominio sobre el territorio, en especial sobre terrenos comunales, áreas de herbajes y recursos hídricos.

Por otro lado, no se descarta la posibilidad de que el repertorio de Inchola sea la plasmación de un programa iconográfico de contenido más simbólico que ponga en relación un determinado tipo de grafismo parietal con el mundo de las mentalidades de la época, usado para purificar un espacio considerado impuro, recurriendo a un ritual de exorcismo popular sencillo, alejado de cualquier procedimiento normativo establecido por la Iglesia. No obstante, la ausencia de motivos cruciformes, que se suponen cumplen una función protectora con claro deseo de cristianizar espacios considerados como paganos (cuevas, abrigos o monumentos megalíticos prehistóricos, o edificios andalusíes), priva a esta posible vía interpretativa del argumento que la dotaría de la solidez necesaria para hacerla más que probable. A pesar de ello, el añadido durante el siglo XVI de detalles aislados, como herraduras, en repertorios medievales realizados sobre muros de edificios en otras zonas del país, testimonia este tipo de prácticas purificadoras en monumentos o lugares relacionados con la población islámica anterior. En cualquier caso, el hecho 
de tratarse de grafitos al aire libre, al igual que sucede con aquellos realizados sobre soportes rupestres situados en un entorno accesible a todo tipo de personas, amplía la variedad de motivaciones (religiosas, entretenimiento, liminales, etc.) a considerar.

Por lo que a datación se refiere, se trata de grafitos realizados, probablemente, en época bajomedieval o moderna, vinculados a los procesos de reocupación del territorio iniciados a partir del siglo XIV, sobre todo una vez que desaparece la inseguridad generada por las algaradas y razzias provenientes del otro lado la frontera y resuelto, definitivamente, el problema morisco. Por tanto, y en base a ello, no hay que descartar una cronología relacionada con un momento avanzado del siglo XVI e incluso del XVII.

El conjunto de grafitos de Inchola tiene un indudable valor histórico dentro del contexto de las manifestaciones gráficas bajomedievales y modernas, hacia las cuales se ha mostrado cierta indiferencia, considerándolas incluso como ejemplos de vandalismo realizados sobre edificios cuyo valor histórico o artístico relegaba estas realizaciones a la categoría de trazos de poco valor. En consecuencia, en su momento no tuvieron la consideración de fuentes de información histórica cuyo contenido difiere y complementa, al mismo tiempo, del aportado por las fuentes arqueológicas o escritas tradicionales, situación afortunadamente superada en la actualidad.

Su valor histórico y etnográfico debería ser suficiente para proteger los grafitos históricos, sea cual sea su técnica de realización o la función que les otorguemos, contemplando acciones específicas de conservación, in situ o extra situ, en el marco de la restauración y rehabilitación de edificios históricos de carácter privado o público, civiles o religiosos; promoviendo un inventario y catalogación de motivos que permita generar un corpus regional que facilite su estudio; considerándolos, en definitiva, como elementos del patrimonio cultural con un tratamiento que ponga de relieve su importancia como fuente histórica, dejando de lado la consideración de elementos anecdóticos, en el mejor de los casos, que ahora tienen.

Inchola cuenta con un conjunto de grafitos en un más que aceptable estado de conservación pese a estar al aire libre, pero este caso no es la norma. La degradación y abandono en el que se encuentran muchos de los lugares que cuentan con este tipo de manifestaciones gráficas, sobre todo aquellos situados en el medio rural, pone en serio riesgo su permanencia. La desaparición de estas edificaciones con los repertorios que contienen sus muros, se llevará consigo una abundante y variada información de gran valor para entender la mentalidad de los grupos sociales sin voz y sin presencia en las fuentes documentales tradicionales. 


\section{BIBLIOGRAFÍA}

Abellán Pérez, J. \& Abellán Pérez, J. M. (1979). Aportación de Murcia a la rebelión morisca de La Alpujarra almeriense: el cerco de Velefique (Octubre de 1500-Enero de 1501). Cuadernos de Estudios Medievales y Ciencias y Técnicas Historiográficas, 4-5, 27-39.

Ardit, M. (2007). La historia rural de la España oriental durante la Edad Moderna: un estado de la cuestión. Studia Historica: Historia Moderna, 29, 47-82.

Balesteros, C. \& Ribeiro, M. (1999-2000). Marcas de cristianizaçao nos núcleos urbanos antigos de Alpalhao e Valencia de Alcántara (Cáceres). Ibn Maruán, 9-10, 391-416.

Barrera Maturana, J. I. \& Cressier, P. (2003). Grabados parietales y rupestres de Almería: un problema de cronología. En González Pérez, J. R. (coord.). Actes del I Congrés Internacional de gravats rupestres $i$ murals: homenatge a Lluis Diez-Coronel. Lleida, 709-720.

Cardoso Dos Santos, J. C. (2018). Arte rupestre nao planalto de Carrazeda de Ansiaes. Contributos para o seu estudo. Arqueología en el valle del Duero. Del Paleolítico a la Edad Media, 6, 60-72.

Castejón Porcel, G. \& Rabal Saura, G. (2018). La Fuente del Alacrán (Los Brianes, Corvera): de manantial de uso público a mina privada. Revista Murciana de Antropología, 25, 165-192.

Castejón Porcel, G. \& Rabal Saura, G. (2019). Aprovechamiento hidráulico de las aguas de la Rambla de La Murta (La Murta, Murcia). Murgetana, 141, 151-181.

Castillo Fernández, J. (2014). Tenemos los enemigos en casa: un supuesto complot entre moriscos murcianos, valencianos, y granadinos para unirse a los rebeldes de Las Alpujarras (1569). Murgetana, 130, 65-87.

Cressier, P. (1992). Grafiti cristianos sobre monumentos musulmanes de la Andalucía oriental: una forma de exorcismo popular. En P. Cressier (ed.), Estudios de arqueología medieval en Almería, 121-148. Almería.

Cressier, P. (1986). Dalías et son territoire: un groupe d'alqueríes musulmanes de la Basse Alpujarra (Province d'Almería). En Actas del XII Congreso de la U.E.A.I. Málaga, 205-228.

Cressier, P. (1986). Grafiti cristianos sobre monumentos musulmanes de la Andalucía Oriental: Una forma de exorcismo popular. En Actas del I Congreso de Arqueología Medieval Española (Huesca 1985), 273-291. Zaragoza. 
Del Castillo, A. (1972). Las insculturas rupestres de la necrópolis altomedieval de Revenga. En Actas del XII Congreso Nacional de Arqueología (Jaén, 1971), 797-800. Zaragoza.

Del Castillo, A. (1974). Los grabados rupestres de Revenga (Burgos). En Miscelánea Arqueológica. XXV Aniversario de los Cursos Internacionales de Prehistoria y Arqueología en Ampurias (1947-1971), 233-243. Barcelona.

Del Rey, L. B. \& Grande Del Brío, R. (1994). Estaciones de grabados rupestres en la comarca cacereña de Las Hurdes. Zephyrus: Revista de prehistoria y arqueología, 46, 215-224.

Del Val Recio, J. \& Escribano Velasco, C. (2004). Guías de lugares arqueológicos de Castilla y León. Salamanca: Junta de Castilla y León.

Erkoreka, A. (1995). Catálogo de huellas de personajes míticos en Euskal Herria. MUNIBE (Antropologia-Arkeologia), 47, 227-252.

Fernández Ibáñez, C. \& Lamalfa Díaz, C. (2005). Manifestaciones rupestres de época histórica en el entorno de la cabecera del Ebro. Munibe (Antropologia-Arkeologia), 57, 257-267.

Gilotte, S. \& Cordero, A. G. (2002). Graffiti murales de época histórica en el Castillo de Monsalud (Nogales, Badajoz). Arqueología y territorio medieval, 9, 249-288.

Gómez-Barrera, J. A. (1993). Tradición y continuidad del arte rupestre en la Antigüedad tardía. Antigüedad y Cristianismo, 10, 433-448.

Gómez-Barrera, J. A. (1991). Contribución al estudio de los grabados rupestres postpaleolíticos de la Península Ibérica: las manifestaciones del Alto Duero". Espacio, Tiempo y Forma, Serie I, 4, 241-268.

Hernández Franco, J. \& Jiménez Alcázar, J. F. (1996). Estado, aristocracia y oligarquías urbanas en el Reino de Murcia. Un punto de flexión en torno a las Comunidades de Castilla. Chronica Nova, 23, 171-187.

Jabato Martín, J. M. (2012). Iconografía y epigrafía pastoril sobre piedra en Los Llanos de Brozas y Alcántara Extremadura. Revista Piedras con Raíces, 34, 12-18.

Lamalfa Díaz, C. (1992). Marcas de término y otros petroglifos en las montañas cántabras. En González Pérez, J. R. (ed.), Actes del I Congrés Internacional de gravats rupestres i murals: homenatge a Lluís Díez-Coronel: (Lleida, 23-27 de novembre de 1992). Lleida, 833-846.

Lemeunier, G. (2004). Población y poblamiento en la región de Murcia, (siglos XVI y XVIII): Censos de población y series bautismales. Áreas: Revista Internacional de Ciencias Sociales, 24, 83-100.

Líbano, I. (2016-2017). Grabados de pastores en las pizarras de Riocavado de la Sierra (Burgos). Kobie, Serie Antropología Cultural, 20, 155-170. 
López Martínez, F. J. (2005). Torre de Inchola (Alhama de Murcia). Memorias de Patrimonio, 7, 37-42.

Martínez Carrillo, M. Ll. (1988). Dehesas y pastos comunes en los finales del siglo XV. Murgetana, 76, 111-121.

Martínez Carrillo, M. Ll. (1988). Dehesas y pastos comunes en los finales del siglo XV. Apéndice cartográfico. Murgetana, 77, 33-34.

Martínez Carrillo, M. Ll. (2004). Jurisdicción concejil y trashumancia en la Baja Edad Media murciana. Murgetana, 110, 43-70.

Molina Molina, A. L. \& Jiménez Alcázar, J. F. (1996). La frontera enquistada: el Reino de Murcia a fines de la Edad Media. Meridies: Revista de Historia Medieval, 3, 51-60.

Mozas Agulló, I. \& Vilar Ramírez, J. B. (1977). Un conflicto de señoríos en la España del siglo XVI: Pleito entre la Villa de Alhama de Murcia y su señor el Marqués de Los Vélez (1548-1592). Estudis: Revista de historia moderna, 6, 27-70.

Padilla, J. I. \& Rueda, K. A. (2011). Los grabados rupestres del despoblado medieval de Revenga (Burgos). Munibe (Antropologia-Arkeologia), 62, 439-459.

Ramírez Águila, J. A. \& Baños Serrano, J. (2005). El castillo de Alhama de Murcia: una fortaleza castellana entre Aragón y Granada». Verdolay: Revista del Museo Arqueológico de Murcia, 9, 255-274.

Ramírez Águila, J. A. \& Baños Serrano, J. (1997). La despoblación como fenómeno de frontera en el valle del Sangonera/Guadalentín (Murcia). Siglos XII-XIV. En Actas del Congreso: La Frontera Oriental Nazarí como Sujeto Histórico (siglos XIII-XVI). Almería, 373-379.

Santos, C. S., Santos, C. A. \& Ballesteros, C. (1999). Marcas de simbologia religiosa judaica e cristá ou cristá-nova nos núcleos urbanos antigos de Estremoz e de Troncoso. En Actas del $3^{\circ}$ Congresso de Arqueologia Peninsular. Vila Real, 207-228. 